\title{
THE FINE STRUCTURE OF THE HUMAN ENDOMETRIAL CILIATED CELL
}

\author{
I. A. R. MORE AND R. G. MASTERTON \\ University of Glasgowe, Department of Pathology, \\ Western Infirmary, Glasgow
}

(Received 17th January 1975)

\begin{abstract}
Summary. Sixty-eight histologically normal specimens from all stages of the menstrual cycle were examined during an ultrastructural study of the human endometrial ciliated cell. The 'clear' ciliated cells found initially were seen to become at first dense and then secretory. These changes are advanced as an explanation to account for the previously observed reduction in frequency of the ciliated cell during the luteal phase. The possibility of an hormonal control mechanism is discussed.
\end{abstract}

\section{INTRODUGTION}

Initially thought to be metaplastic in origin (Fruin \& Tighe, 1967), ciliated cells are now accepted as integral components of the uterine epithelium (Ferenczy et al., 1972). Several authors have described their light microscopic appearances (Hamperl, 1950; Schueller, 1961, 1968). The ultrastructure of the ciliated cells has been largely ignored, however, in favour of its more numerous counterpart - the glandular cell (Borell et al., 1959; Armstrong et al., 1973). The cyclical variations in frequency of the ciliated cell have been determined (Masterton et al., 1975), but their function and fate are unknown. The present work was carried out to investigate the ultrastructure of the endometrial ciliated cell.

\section{MATERIALS AND METHODS}

Tissue was obtained by diagnostic curettage from 68 women between the ages of 17 and 44 years. Thirty-five women were undergoing laparoscopic sterilization and a further twenty had presented for investigation of minor menstrual irregularities. The remainder were being investigated for either primary or secondary infertility. The tissue obtained was divided into two portions. The first was fixed in buffered $4 \%$ formaldehyde $(\mathrm{pH} 7 \cdot 3)$ and, after dehydration and embedding in paraffin wax, $5 \mu \mathrm{m}$ sections were cut and stained for routine light microscopic examination. The other portion of tissue was cut immediately into $1-\mathrm{mm}$ cubes, fixed in buffered $4 \%$ glutaraldehyde ( $\mathrm{pH} \mathrm{7.3),} \mathrm{post-fixed} \mathrm{in}$ osmium tetroxide, dehydrated and embedded in Araldite. Thin sections were cut on an LKB ultramicrotome, stained with uranyl acetate and lead citrate and then examined in a Philips 301 electron microscope. 


\section{RESULTS}

Light microscopy. All specimens appeared histologically normal when examined with the light microscope.

Electron microscopy of ciliated cell. In the early proliferative phase the ciliated cell precursor first appeared in relation to the basement membrane at the bases of endometrial glands. This cell was non-ciliated, and contained a small round central nucleus with a rim of partly condensed chromatin (Pl. 1, Fig. 1). The cytoplasm, which was less electron dense than that of the surrounding glandular cells, contained variable numbers of small mitochondria clustered round the nucleus. Poorly developed rough endoplasmic reticulum was sometimes present but neither Golgi apparatus nor smooth endoplasmic reticulum could be found. The cell membranes tended to be smooth and without marked infoldings. As the cycle progressed, the ciliated cell precursor could be seen in various positions between the basement membrane and the gland lumen. The cell increased in size and the nucleus became larger, containing vesicular chromatin. The mitochondria, still perinuclear, were larger and more numerous, and ciliogenesis was occurring. At the gland lumen, the cells were classically shieldshaped (Pl. 1, Fig. 2) with cilia and microvilli at the luminal surfaces. Large numbers of mitochondria were now present, almost entirely in an apical concentration. The other organelles, initially scanty and poorly developed, became more prominent as the cycle progressed; Golgi apparatus and smooth endoplasmic reticulum were visible, and occasional glycogen aggregates were present. In the late proliferative and ovulatory periods, ciliated cells with

\section{EXPLANATION OF PLATES}

\section{PLATE 1}

Fig. 1. Ciliated cell precursor of human endometrium situated at basement membrane (arrow). Note for comparison lymphocyte present within epithelium. $\times 6000$.

FIg. 2. 'Clear' ciliated cells. The cell on the right has the classical 'shield' shape. Note the 'clear' cytoplasm, apical mitochondrial concentrations and the large rounded vesicular nucleus. The left-hand cell has extended down to the basement membrane, and basal mitochondria are present. $\times 4000$.

\section{PLATE 2}

FIG. 3. Dense ciliated cell of human endometrium. Note the markedly dilated Golgi apparatus $(G)$ and the masses of glycogen $(\mathrm{Gl}) \times 7200$.

FIG. 4. Ciliated cell showing secretory bleb. $\times 27,000$.

PLATE 3

Fig. 5. Rhizoplasts in ciliated cell of human endometrium. Note the way in which the microfilaments $(\mathbf{M})$ originating from the basal bodies (B) fuse to form larger bundles. $\times 34,000$.

Frg. 6. Basal bodies. A microtubule is seen joining the lateral satellite of a basal body (arrow). $\times 39,000$.

Fig. 7. Basal bodies. Note the transverse banding of the basal bodies. A microtubule is shown joining a basal body at an area of dense banding (arrow), and microfilaments $(\mathbf{M})$ are seen spreading out from an adjacent basal body. $\times 35,000$.

Fig. 8. Basal body. Note the vesicle. Connections from basal body to cell surface are shown (arrow). $\times 39,000$.

Fig. 9. Cilia showing the 'blistered' nature of the ciliary coat. $\times 39,000$. 

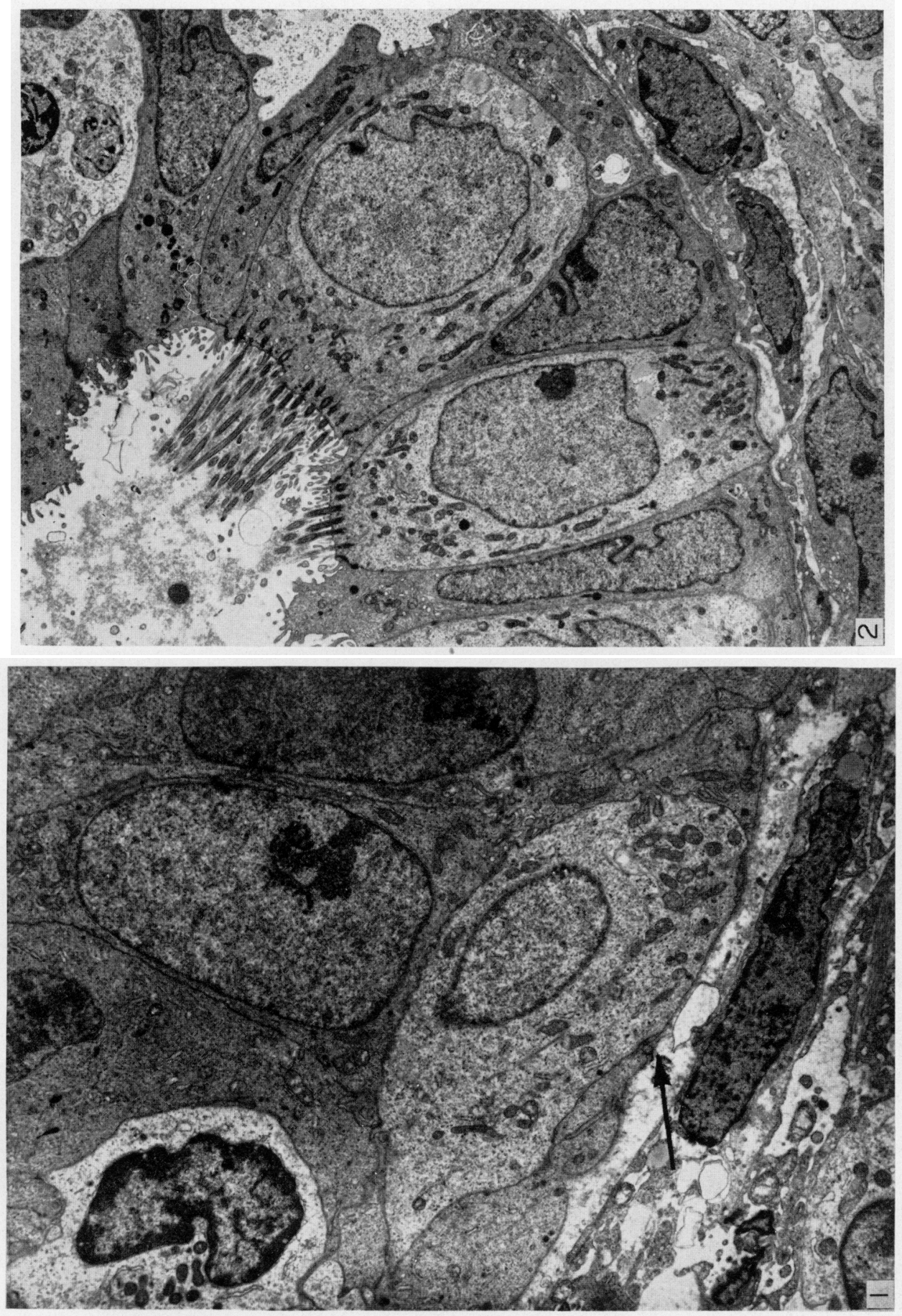
PIATE 2
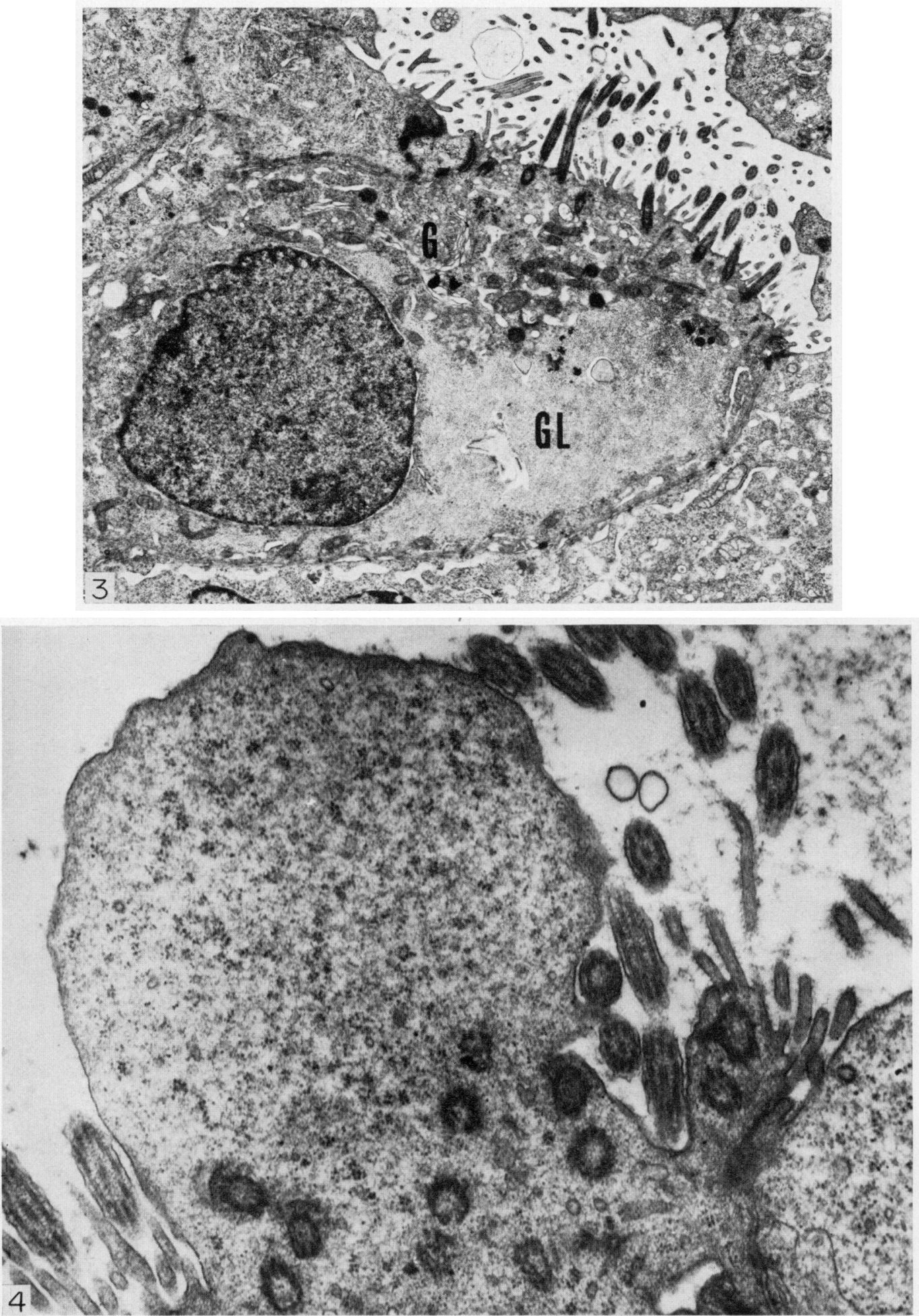
PLATE: 3
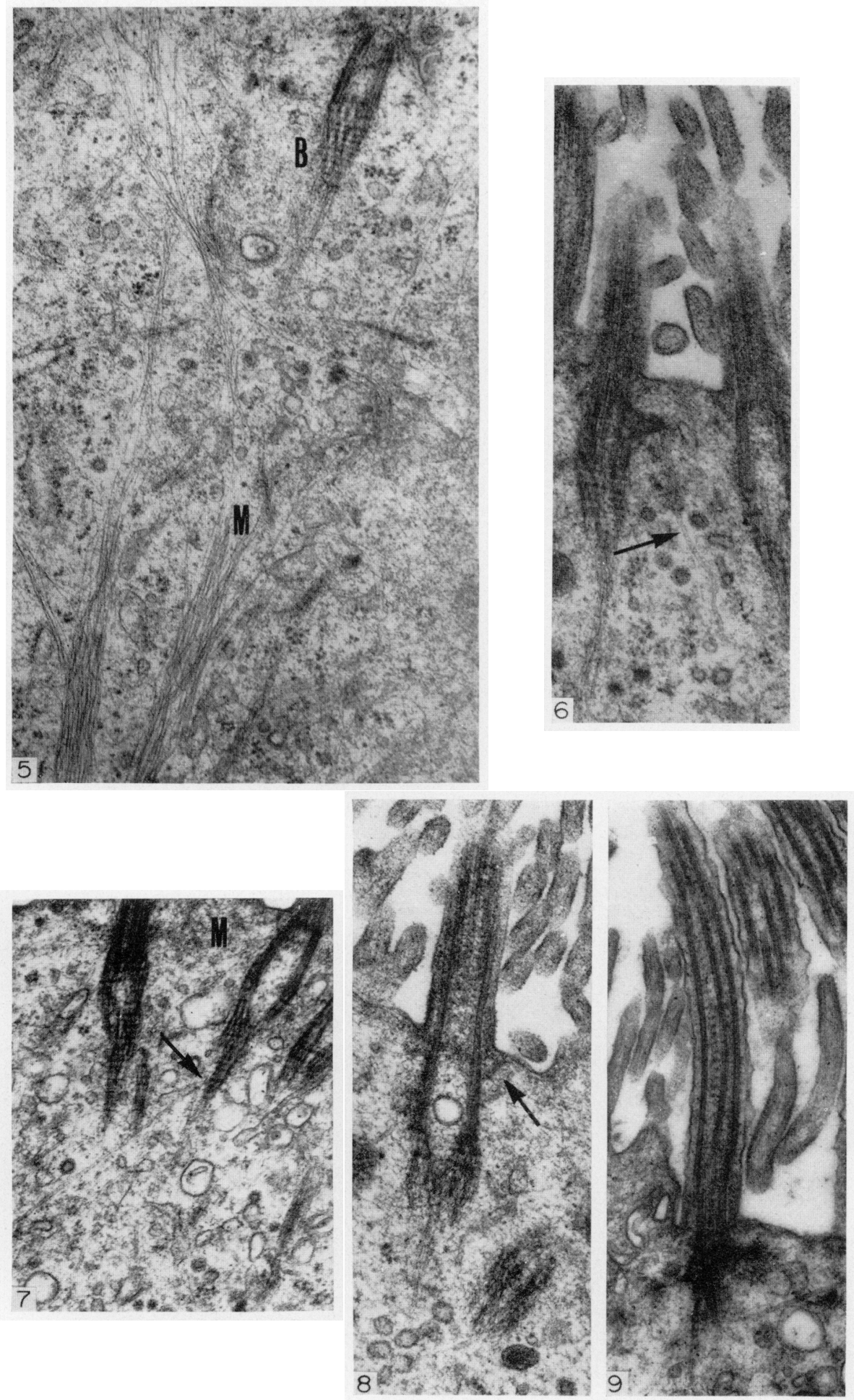
broader luminal surfaces were seen and tall columnar ciliated cells were also found (P1. 1, Fig. 2). The cell membranes became more convoluted and the cytoplasmic matrix gradually denser until it resembled that of the neighbouring glandular cells. Mitochondria, though still concentrated mainly at the apex, could now be found throughout the cytoplasm. The remaining cell organelles were better developed, and the rough endoplasmic reticulum reached its peak early in this phase. Microtubules were free in the cell cytoplasm and glycogen aggregates became more conspicuous.

These changes continued as the cycle progressed until all the ciliated cells were of tall columnar shape with dense cytoplasm. At this time, the secretory stage, the cell membranes were more tortuous with the basement membrane markedly undulated. Although exceptions occurred, ciliated cells did not generally contain as much glycogen as their glandular counterparts (Pl. 2, Fig. 3). Secretory blebs on ciliated cells, comparable with those of surrounding glandular cells, were found. Although a few microvilli and cilia could be seen on either side, the blebs themselves were 'bald' and contained few if any cell organelles. The orientation of the cilia was disturbed by the upthrusting secretory protrusion and the cilia thus appeared as a compressed fringe around the bleb. There was a concomitant reduction in mitochondrial numbers, the majority being lost from the apical zone (P1. 2, Fig. 4). No giant mitochondria or nucleolar channel systems were found.

Electron microscopy of ciliary apparatus. The basal bodies were found in rows just below the surface of the mature ciliated cells. The rhizoplasts, which converged as they extended into the cytoplasm, originated from the bases of the basal bodies as bundles of microfilaments (Pl. 3, Fig. 5). No anchorage points for these microfilaments were found. The basal bodies themselves were cone shaped and of various lengths. In transverse section the thinner bases appeared as conglomerations of microfilaments although the characteristic centriolar structure was shown at the broader tips. In longitudinal sections the basal bodies exhibited a banding with a periodicity of $65 \mathrm{~nm}$. Electron-dense lateral satellites could be seen near the top of the basal bodies. Microtubules joined the basal bodies at the lateral satellites (Pl. 3, Fig. 6) and at the areas of dense banding (Pl. 3, Fig. 7). Above the lateral satellites microfilaments could be seen to spread out from the basal bodies parallel to the cell surface (Pl. 3, Fig. 7), and connections with the cell surface were identified. Small vesicles were occasionally found centrally placed within the basal bodies and proximal axonemal complexes (Pl. 3, Fig. 8).

The axonemal filaments appeared above the level of the basal bodies. When cut in transverse section below the level of the cell surface they were formed of nine peripheral double filaments with a central mass of microfilaments. When cut in transverse section above the level of the cell surface, the $9+2$ filaments were seen to have an outer membranous coat characteristic of ciliary structures. From one to twenty cilia were found in any one cross-section, and sometimes they were atypical. The abnormality was often a structural one involving the addition or deletion of one or more of the peripheral or central filaments, but occasionally grossly altered cilia were present. The frequency with which these abnormal forms were found varied, not only from sample to 
sample, but also from cell to cell. In general, however, where there was one abnormal cilium there tended to be many more. Longitudinal sections showed cyclical variations in the ciliary membranes which were initially smooth but which became progressively roughened and 'blistered' (Pl. 3, Fig. 9).

\section{DISGUSSION}

As ciliated cells arise throughout the proliferative stage of the menstrual cycle so, with the exception of the early proliferative and late secretory phases, they show no structural uniformity in relation to time.

At the start of the cycle there are no ciliated cells. Hamperl (1950) identified a small cell found at the endometrial basement membrane which he suggested might be the ciliated cell precursor. Schueller (1968) studied ciliogenesis occurring in a migrating population of 'clear' cells. The apparent similarity of ultrastructure between these cell types would support the theory that the latter is derived from the former. The predominance of mitochondria in the cells undergoing ciliogenesis compared to the dormant precursor cells reflects the increased metabolic activities. It is possible that the 'clear' and ciliated cells found early in the menstrual cycle may not have moved as units to the luminal surface of the epithelium but may in fact have retained some contact with the basement membrane. However, no such contacts were observed in any of the numerous specimens examined from the early or mid-proliferative stages.

During the proliferative phase the classical 'clear' ciliated cell (Mandl, 1911) can be found at the gland lumen. The cytoplasm of these cells is less electron dense than that of the surrounding glandular cells. Confusion arises with use of the term 'clear' as other cells have a similar appearance in the electron microscope, e.g. lymphocytes. Since, however, lymphocytes tend to have a higher nuclear to cytoplasmic ratio and a more condensed chromatin pattern contained in a markedly irregular nucleus, it is generally easy to differentiate between the two cell types. Several factors lead to the reduced density of the ciliated cells: the cytoplasm appears more amorphous and contains few organelles, which are themselves poorly developed (Schueller, 1973). The mitochondria, concentrated at the cell apex, are presumably necessary to provide the ATP needed for ciliary movement. As the cycle progresses so other cell organelles, especially the Golgi apparatus and the smooth endoplasmic reticulum, become more prominent. The nuclear chromatin at this time is in the active euchromatin form, reflecting the need for the increased mRNA required for the synthesis of new proteins. As these changes continue so glycogen aggregates appear and the density of the cytoplasmic matrix increases. Thus the 'clear' ciliated cell is transformed into its denser counterpart.

Later in the cycle the dense ciliated cells show a markedly dilated Golgi apparatus and contain masses of glycogen. Thus these cells may be involved in the production and subsequent cellular expulsion of secretory material. Associated with the secretory activity is a reduction in the numbers of cilia and a concomitant loss of apical mitochondria. The nuclear appearances at this time suggest a cell less involved in production of $\mathrm{mRNA}$, both metabolic and synthetic activity being reduced. 
Despite the widespread occurrence of cilia their structure varies little between different organs (Satir, 1965). Although basal bodies are said to be formed by centriolar reduplication, this explanation does not account for their different ultrastructural characteristics (Satir, 1965; Toner \& Carr, 1972; Schueller, 1973). As their microfilaments become confluent we feel that rhizoplasts may form not only part of the ciliary motor mechanism (Schueller, 1973), but also a co-ordinating control for ciliary beat.

The endometrium is unusual in that it shows such a high degree of ciliary atypia (Hando et al., 1968; Armstrong et al., 1973), which generally consists of addition or subtraction of one or more of the ciliary filaments. Although recent work on ciliary movement (Satir, 1974) may explain some of the minor structural irregularities, it does not account for the grosser anomalies.

Vesicles are known to be present in the ciliary apparatus of other life forms (Satir, 1965) but have not been previously reported in the reduplicated centrioles and cilia of endometrial cells. In the endometrial cell, the vesicles were found most frequently in the centre of either the basal body or proximal axonemal complex; previously the vesicles have been described as occurring at any height in the cilia and always outside the axonemal filaments. These vesicles are associated with ATP transport, the ATP providing the necessary energy for ciliary motion. Whereas endometrial cilia are 8 to $10 \mu \mathrm{m}$ in length (Nilsson \& Nygren, 1972), those found at other sites may measure up to $100 \mu \mathrm{m}$ (Satir, 1965). Thus the difference in vesicle positions may reflect the different functional requirements of energy transport in endometrial cilia.

As the cycle progresses, the ciliary membranes exhibit structural changes and become increasingly rough and 'blistered'. Johannisson \& Nilsson (1972) suggested that this represented degenerative changes in the cilia. Although the blistered areas may merely reflect the increased cell surface membrane associated with secretory activity (Johannisson \& Nilsson, 1972), we noted a reduction in the numbers of cilia on the surfaces of the secretory ciliated cells and this supports the occurrence of ciliary degeneration.

Light microscopic studies of secretory or dense ciliated cells cut transversely would appear as normal glandular cells. This would account for the previous confusion regarding the frequency of ciliated cells later in the cycle (Fleming et al., 1968; Schueller, 1968; Johannisson \& Nilsson, 1972; Ferenczy et al., 1972). Our work indicates that the reported reduction in numbers in the secretory phase (Masterton et al., 1975) is only an apparent loss due to secretory activity, a previously unreported role for ciliated cells.

The control mechanisms for ciliated cells are as yet undetermined; the cyclical and structural changes in the ciliated and glandular cell populations appear to be similar (Armstrong et al., 1973; Cavazos et al., 1967), and thus the same hormones may influence both cell types. However, the nuclear channel system and giant mitochondria which have been shown to be hormonedependent in the glandular cells (Kohorn et al., 1972) do not occur in the ciliated cells, and hence the basic control mechanism may be manifested in a different fashion in the ciliated cells. 


\section{REFERENCES}

Armstrong, E.M., More, I.A.R., McSeveney, D. \& Chatrield, W.R. (1973) Reappraisal of the ultrastructure of the human endometrial glandular cell. f. Obstet. Gynaec. Br. Commonw. 80, 448-460.

Borell, V., Nilsson, O.J. \& Westman, A. (1959) The cyclical changes occurring in the epithelium lining the endometrial glands. Acta obstet. gynec. scand. 38, 364-369.

Gavazos, F., Green, J.A., Hall, D.G. \& Lucas, F.V. (1967) Ultrastructure of the human endometrial glandular cell during the menstrual cycle. Am. F. Obstet. Gynec. 99, 833-854.

Ferenczy, A., Richart, R., Agate, F.J., Jr, Purkerson, M.L. \& Dempsey, E.W. (1972) Scanning electron microscopy of the human endometrial surface. Fert. Steril. 23, 515-521.

Fleming, S., Tweeddale, D.N. \& Roddick, J.W. (1968) Ciliated endometrial cells. Am. F. Obstet. Gynec. 102, 186-191.

Fruin, A. \& Tighe, J.R. (1967) Tubal metaplasia of the endometrium. F. Obstet. Gynaec. Br. Commonw. 74, 93-97.

Hampert, H. (1950) Über die "hellen" flimmerepithelzellen der menschlichen Uterusschleimhaut. Virchows Arch. path. Anat. Physiol. 319, 265-281.

Hando, T., Okado, D.M. \& Zamboni, L. (1968) Atypical cilia in human endometrium. F. Cell Biol. 39, $475-481$.

Johannisson, E. \& NiLsson, L. (1972) Scanning electron microscopic study of the human endometrium. Fert. Steril. 23, 613-625.

Kohorn, E.I., Rice, S.I., Hemperly, S. \& Gordon, M. (1972) The relation of the structure of progestational steroids to nucleolar differentiation in human endometrium. F. clin. Endocr. Metab. 34, 257-265.

MANDL, L. (1911) Flimmerndes und sezernierendes Uterusepithel. Z. Geburtsh. Gynäk. 34, 150-159.

Masterton, R.G., Armstrong, E.M. \& More, I.A.R. (1975) The cyclical variation in the percentage of ciliated cells in the normal human endometrium. F. Reprod. Fert. 42, 537-540.

Nilsson, O.J. \& NYGREN, K.G. (1972) Scanning electron microscopy of human endometrium. Upsala $\mathcal{F}$. med. Sci. 77, 3-7.

SATIR, P. (1965) Structure and function in cilia and flagella. Protoplasmatologia 3, 1-52.

SATrR, P. (1974) How cilia move. Scient. Am. 231, 44-52.

SchuEller, E. (1961) Epithelien und Stromazellen des menschlichen Endometriums. Arch. Gynäk. 196, $49-66$.

Schueller, E. (1968) Ciliated epithelia of the human uterine mucosa. Obstet. Gynec., N.Y. 31, 215-223.

SchUzLler, E. (1973) Ultrastructure of ciliated cells in the human endometrium. Obstet. Gynec., N.Y. 41, 188-194.

Toner, P.G. \& CARR, K.E. (1972) Cell Structure, 2nd edn, p. 75. Churchill Livingstone, Edinburgh. 